\title{
صيانة وترميم البيت في العراق القديم
}

أ.د. طالب منـعم هبيب / كلية التربية / جامعة واسط

م.م. احمد بشار جمعه / كلية التربية / جامعة واسط الته

الإقدمهة:

يعد البيت أحدى الاوجـه العماريـة التي تنطوي تحت مسمى العمارة المدنيـة، لهذا ارتنينـا في البدء توضيح مفهوم مصطلح العمـارة المدنيـة لكي ينسنى للقارئ فهم مدلو لاتها وأنواع المظـاهر العماريـة التي لـي

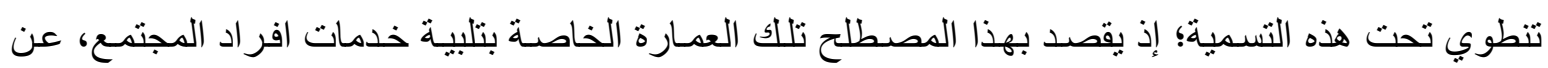
طريق توفير المأوى الجيد بما تحمله هذه الكلمة من معنى شامل لكل ابعاد السكن وملحقاته الخاصـة و العامـة، فهي تمثل العمارة الثـعبية التي يحدد اسلوبها وطرق بنائها وتصـاميمها من تأثر هـا بالبيئة الطبيعيـة والمنـاخ العام للمنطقة، وهذا النوع من العمارة يكون خاضعاً إلى عملية التطور والتغير المستمر نتيجة لتطور الفكر بهر الفني العماري للإنسان('). فالمظهر العماري المدني يمثل هوية الفرد معبراً من خلاله عن شخصيته، باعتباره

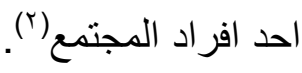

لقد شهدت أرض العر اق القديم مجموعة من المر احل التطوريـة في كافـة الأوجها الحضـارية ابتدأت من اكتشاف الزراعة(؟). وصو لاً إلى اختراع الكتابة التي عن طريقها كان الحد الفاصل بين عصور مـا قبل التاريخ و العصور التاريخية التي أستقر فيها الإنسان في مر اكز مدنية متحضرة سو اء على شكل دويـلات مدن

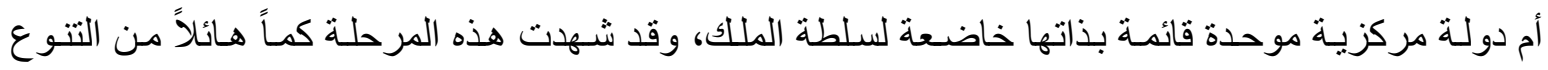
و الانجاز الحضاري خاصةُمًا يتعلق بالجانب العماري المدني من تخطيط و انشـائها واعـادة بنـاء مدن وتجديد

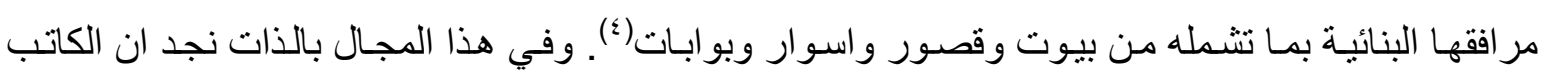
العر اقي القديم قد نرك كماً هائلاً من النصوص البنائية تمثلت بالمنجزات و المشاريع المعمارية من قبل السلطة

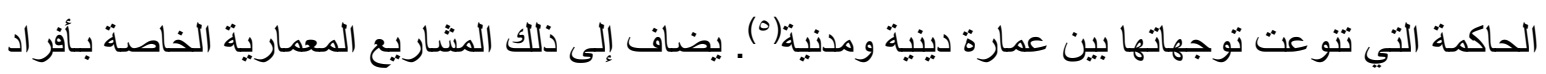
المجتمع سواء ما تعلق بتخطيط البيت وتتيده أم تجديد الذي يعد جز عاً من منظومة أكبر تسمى بـالحي السكني

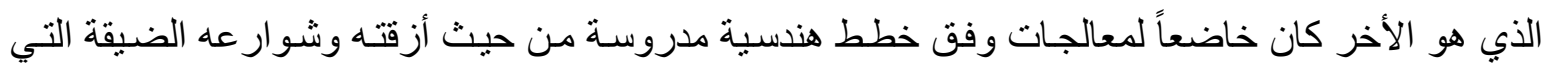

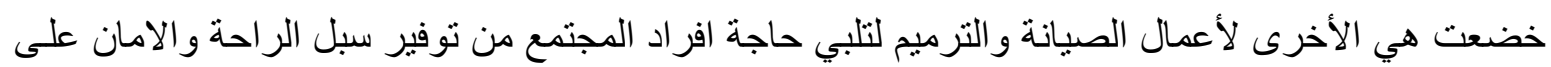
طول اوقات السنة(?).

وردت كلمة البيت في النصوص العر اقية القديمة بعدة صيغ ودلالات ومعان لغوية، فجاءت بالصيغة

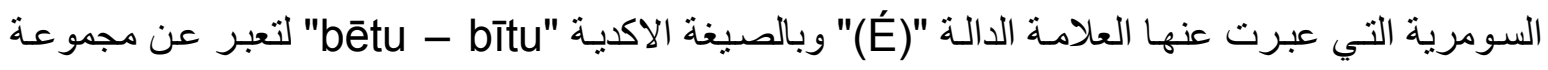

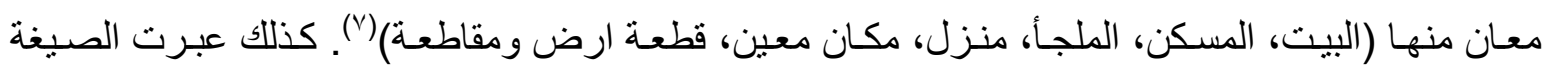

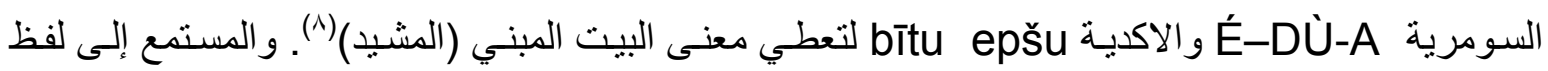
(bîtum) الغريب؛ إذ كلا اللغتين ينحدران من عائلة لغوية واحد متمثلة باللغة الجزرية الأم. 
كذلك يـل المقطع الثـاني الذي تتكـون منـه كلمـة كيبـار متمـثلاً بـالمقطع الاكدي par على معنى السكن('). و هو ذو معنى شامل لم يحدد نوع او ماهية هذا السكن سوى مـا يتعلق بمكان مبيت الكاهن. كذلك

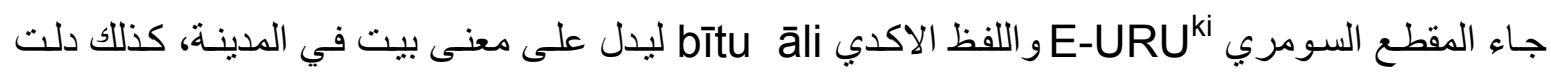
الصيغة السومرية É-UR4-UR4 والاكدية bìt hammūti على معنى مشنملات(r'). أثناره إلى البيت الصغير

لقد تطرقنا في بداية البحث عند حديثنا عن البدايات الأولى لجذور الصيانة والترميم وبينا كيفيـة قيام انسان عصور ما قبل التاريخ معالجته واصلاح الأضرار التي تصيب مؤو آه واعطينـا أكثر من شـاهد لموقع أثرية من ارض العر اق القديم معتمدين في ذلك على نتائج التتقيبـات ومـا توصل اليه المختصين من نتائج التنقيب.

إن عملية الصيانة والترميم كانت وليدة الحاجة و الفطرة معاً، فالإنسان القديم كان يسعى دائماً لإيجـاد

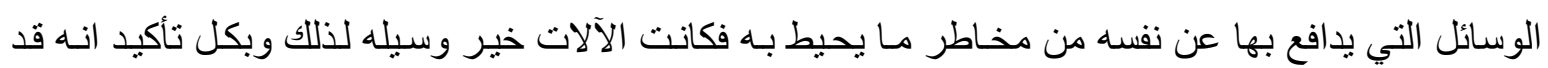
أجرى التعديل و الاصـلاح لوسـائل الدفاع والصيد البسيطة البدائية تلك من أجل المحافظة على حياته، فهذه

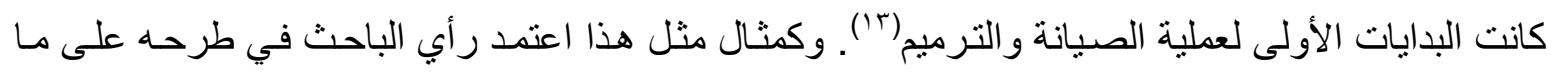

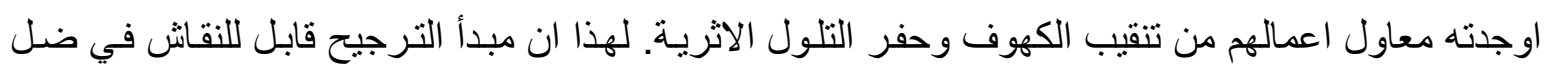
غياب الدليل العلمي الثابت من نص مدون الذي يعطي كلمـة الفصل في حدوث أمر الصبيانة والترميم أم لا.

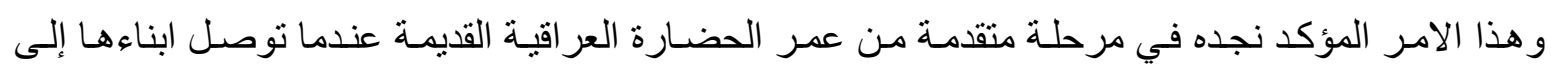
اختر اع الكتابة كوسيلة للتدوين التي كانت خير دليل معطاء ساعدت الباحثين في الوقوف على مجمل انجـاز ات

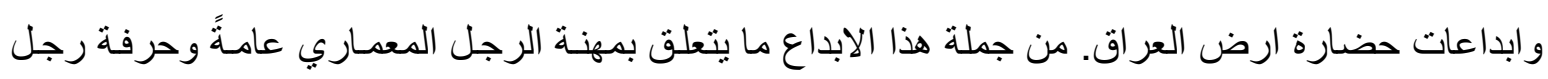
الصيانة والترميم خاصـة؛ إذ امدتنا النصوص المسمارية بكم هائل من الاشـار ات الكتابيـة بما يتعلق بـأمور تجديد مظاهرة المدنية من (بيوت، مدن، قصور، طرق، اسوار وبوابات) كل هذا المظاهر العمرانيـة جرت عليها عمليات صيانة وترميم من قبل افراد المجتمع سو اء كانت بأمر من السلطة الحاكمة ام بجهود فردية. وقد وصفت ارض سومر بالبيت الكبير في نصوص الادب العر اقي القديم كما في النص التالي: "....أيها البيث - يا سومر - عسى أن تثيد حظائرك العديدة. وعسى أن تثضاعف أبقارك.."(؛ "). لقد شهدت البيوت العر اقية القديمة جملة من التطورات و التحديثات في مظهر ها العام سواء مـا تعلق بشكلها الخـارجي أم تنظيم وترتيب بنيتها الداخليـة، لهذا دلت نتائج التنقيب عن تصـاميم ورسومات هندسية للبيوت بشكل مختلف من فتره لأخرى؛ إذ نجدها أخذت بالتطور التدريجي من الثكل الدائري إلى المستطيل

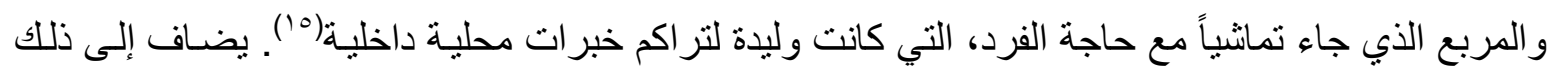

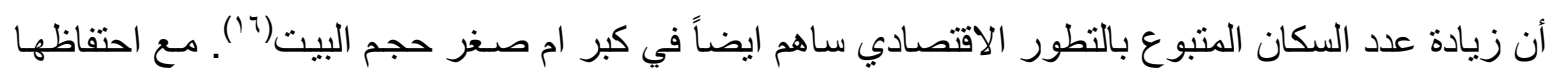
بأهم سمه تميزت بها عبر تاريخها الطويل سواء كان ذلك في عصور مـا قبل التاريخ ام العصور التاريخية

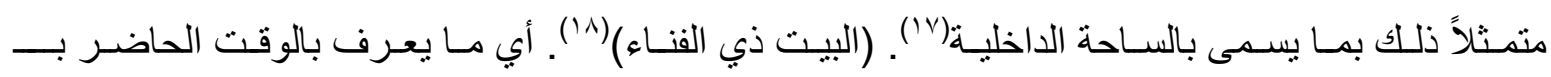

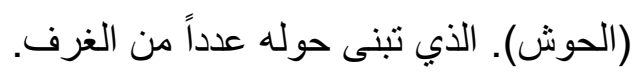


ولقد كان البيت السومري في النصف الأول من الالف الثالث قبل الميلاد يتكون من طابق واحد وفي

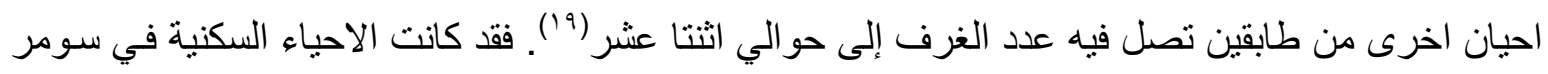

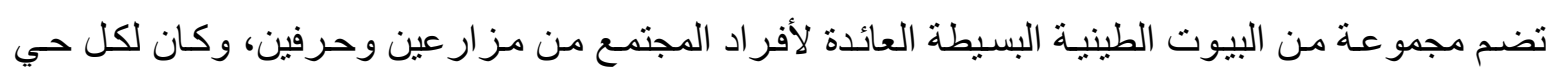

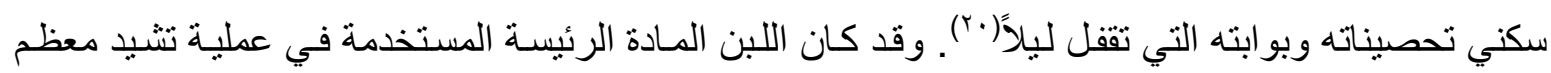
اجز اء البيت العر اقي القديم منذ فجر التاريخ، لهذا كانت مسألة التنقيب واستخلاص النتائج العلميـة للمظـاهر

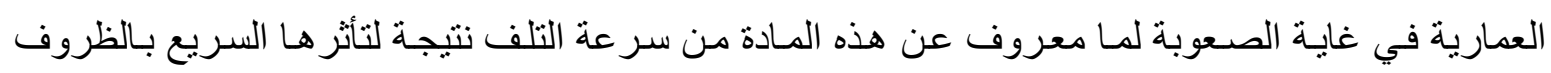

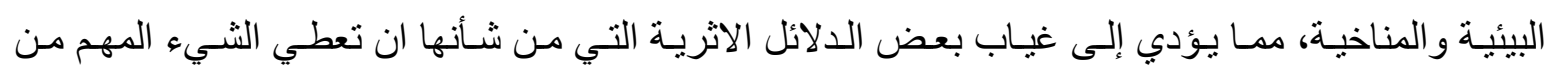

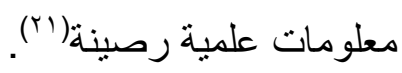

لقد دلت النصوص المسمارية المكتشفة والعائدة لفترة زمنية مختلفة من مرحلة العصور التاريخية في

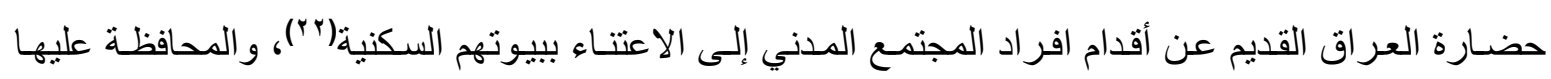

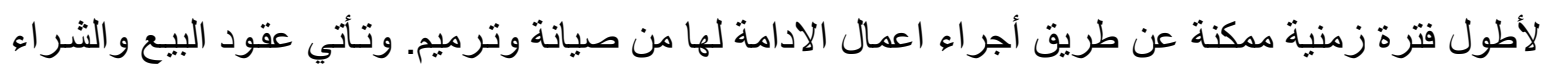

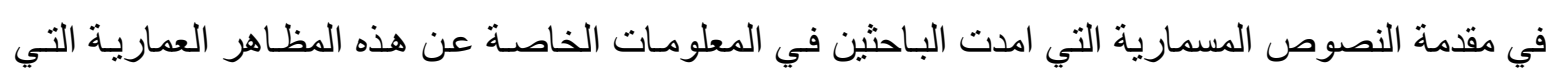
اوضحت مجموعة من تفاصيل واجز اء البيت، كما في النص التالي:

"بيت مبنـي مـع دعامـته وبابـه، وفنائهـ المبنـي وحمامـه وجنـاح خدم البنايـة الرئيسـة، وطابق ثـان

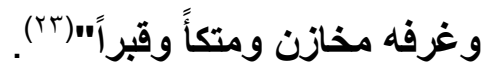

وتتو عت الاسباب التي دفعت الانسان إلى تجديد منزله منها مـا يتعلق بالجانب العاطفي و النفسي من حبه لبيئته ومكان طفولته الذي عاش وتربى فيه، وهذا الامر نجده و اضحاً في النص التالي: "أياً كان تسيل دموعه الى الاسفل عندما يترك بيته القديم ويبني واحداً جديداً"(؛ r).

النص اعلاه يوضح صعوبة ترك الانسـان بيته القديم والذهاب إلى اخر جديد وقد يكون سبب ذلك هذا لتعلقه بماضية وجذوره التي يبقى متمسكاً بها، فكان هذا الامر من جملة امور اخرى جعلته يأبى الانتقال

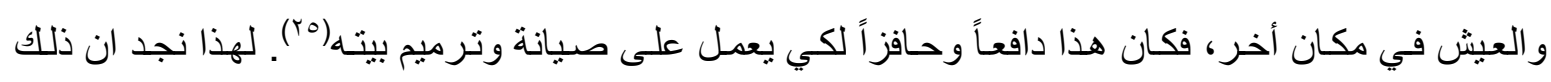

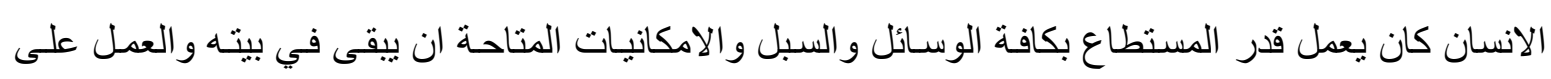
تجديده حتى وان كان في ذلك صعوبة وارهاق على نفسه، و هذا ما يبينه احد النصوص التالية:

"هو قوى (البيت، وجدد المستطاع منه) وأعاد بناء (ما لا يمكن اصلاحه)"(بr).

النص اعلاه يشير إلى عملية ترميم بيت وصل به الخراب إلى اماكن وجد صاحب العمل صسعوبة في

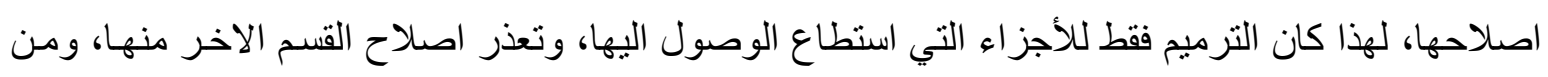
فحوى النص اعلاه ان الثخص المشرف على العمل كان قليل الخبرة والدرايـة بـأمور البناء فمن المككن ان يكون ماللك البيت هو من قام بعملة التجديد.

وفي احيان اخرى تتير النصوص المسمارية إلى آلية اعمال صيانة وترميم البيوت الخاصة بالإيجار عن طريق اتفاق يبرم بين المؤجر و المستأجر . كما في النص التصالي: 


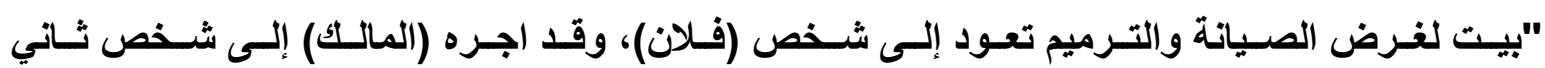

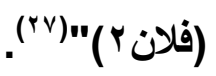

فالنص اعلاه يشير إلى اقدام شخص بتأجير بيته إلى شخص ثنان مع تكفله بتجديد الاجزاء المتهالكة

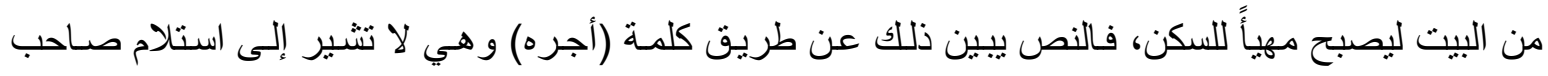
البيت قيمه نقدية مقابل تأجيره للبيت و انما القيمة النقدية التي سيقدمها المستأجر مقابل فترة سكنه هي التعهد بإصلاح كافة اضر ار البيت بدليل ان البيت وصف على انه (للصيانة والترميم).

و اثشارت العديد من النصوص المسمارية التي تضمنتها مواد القو انين العر اقية موضوع الامو ال الغير منقولة من ار اضي وبيوت سواء مـا يتعلق بمأمور البيع والثـر اء وكذللك اولت اهتمـام بجانب ايجـار البعض لهض منها، فأوضحت العلاقة بين مالك البيت و المؤجر؛ إذ وضعت شروط و آليات حددت بموجبها ضمان حقوق كلا الطرفين(^^). كما في النص التالي:

"اذا أجر رجل داراً لرجل آخر لمدة سنة واحدة، والمؤجر قد دفع لصاحب الدار الايجار كاملاً حسب العقد ولمدة سنة واحدة. فاذا طلب صساحب الدار من المؤجر ان يخلي (الدار) قبل الموعد (أي قبل انتهاء السنة)، فعلى صاحب الدار لكونه قد طلب من المؤجر ان يخلي (الدار) قبل الموعد، أن يخسر النقود التي

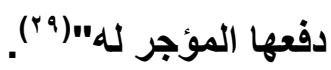

النص اعلاه احدى المواد القانونيـة الخاصـة بقانون حمور ابي الذي يوضـح الاحكام الخاصـة بإيجار

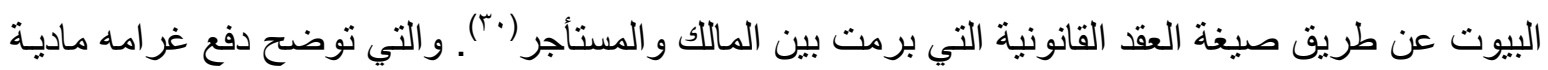

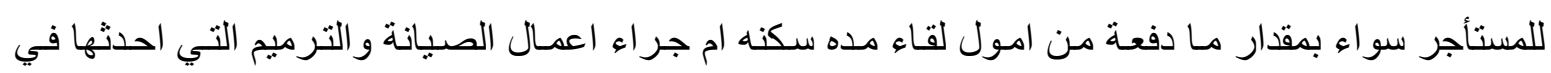
البيت. كما هو واضح في النص الآتي:

"إلى ان يدفع الفضة كنفقات (المستأجر) المنفقة لتحسين الارار"("آ).

وفي احيان اخرى تكون اعمال الصيانة والترميم التي قام بها المستأجر مصحوبه بنوع من الغر امة المترتبة على اي طرف من اطر اف عقد صيغة الايجـار، وبخصوص هذا الموضوع نجد ان العديد من النصوص المسمارية قد اشارت إلى هذا الجانب. كما في النص التالي: "فيما يتعلق بالتحسينات التي سيضعها المستأجر في البيت، متى ما قال صاحب الدار إلى المستأجر غادر البيت، (فان المستأجر له الحق في هلم التحسينات التي أجراهـا على البيت)، ولكن في الوقت الذي يغادر فيه المستأجر (الدار) بمحض إرادته فأنه سوف يخسر تلك التحسينات (لا يقوم بهرمها)" (بّا). النص اعلاه يتتابه مع النص السابق من حيث وجود صيغة عقد للإيجار بين الملك و المستأجر، لكن

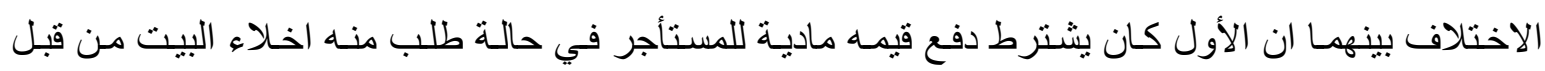
مالكهِ، ان الملفت للنظر في النص اعلاه انه يثنير إلى أحقية المستأجر في ازالة أي بنـاء تم انثـاءه، ممـا تؤكد لنا هذه الصيغة القانونية ان المستأجرين كانوا يقدمون على اقامة اعمال عمر انية في البيوت التي يستأجرونها

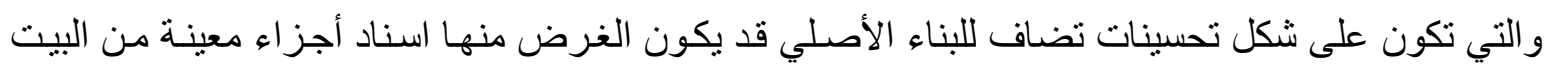


بعد اصـابها بالتلف أو انها كانت مهددة بالانهيار أو ان سبب الثروع لإنجاز هذه الاعمـال العمرانيـة كان من أجل ترميم البيت سواء كان هذا العمل لغرض الجمالية من طلاء الجدران وتحسين بنية البيت من وارضيات

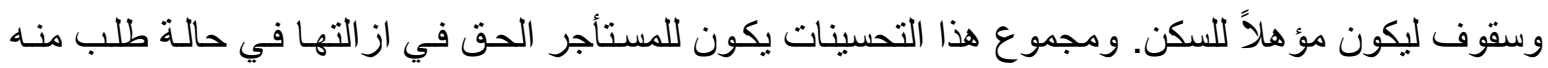
ترك البيت قبل الفترة المحددة له أما اذا ترك البيت بمحض ار ادته فيكون ليس من حقـة از التها وانمـا تصبح ضمن ملكية البيت العائدة لمالكهِ، وهذا الامر كان معمول بـه في فترة العصر البابلي القديم كما اثـارت إلى لى ذلك المو اد القانونيـة. كذلك بينت مواد قانون حمور ابي المتعلقة بترميم البيوت مسؤولية صـاحب البيت عن امور العمل التي تجرى لتجديد البيت؛ إذ انهـ يتحمل مسؤولية كافة التبعـات القانونيـة من اضـرار قد تلحق بأملاك المستأجر التي يصيبها الخراب والتلف جراء اعمال الصيانة والترميم التي تجرى من قبل المالك اثناء

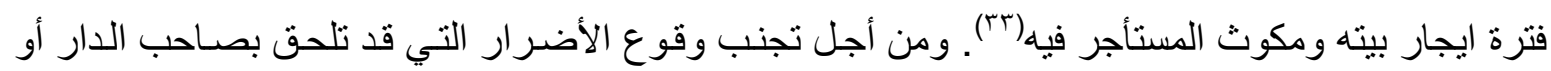

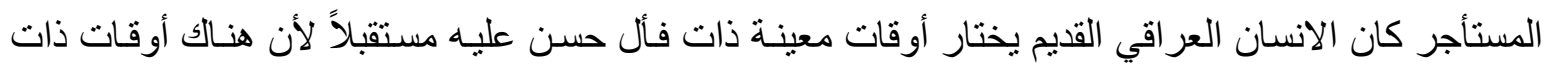
فأل سيء لا تصلح فيها أجر اء عمليات تجديد وترميم لبيته فمجرد الاقدام على تجديد بيته في هكذا أوقات فأنه الهـ سوف يصاب بأذى يصل إلى موته. كما في النصوص التالية:

"إذا جدد شخصٌ ما من نيسان فصاعداً فناء الارار، فلن تكون الصحة والعافية من نصيبهُ".

"إذا جدد شخصٌ ما في نيسان الكبيس فناء الدار، فسوف تزول ثروتهُ". "إذا جدد شخصٌ ما في إيار فناء الدار، فالثخصنُ المعني سيجد نفسهُ إمام عدوهُ"(؟؟). كما تثير النصوص المسمارية العائدة لفترة العصر البابلي القديم إلى طلب أحد الاشخاص من جاره بضرورة نرميم جدار مشترك بينهما؛ إذ يوضح النص استجابة الطرف الثناني إلى طلب الثخص الأول دون تردد مما يعكس النص دلاله اجتماعية تتعلق بحسن التعامل بين افر اد المجتمع العر اقي القديم. وهذا مـا يشير

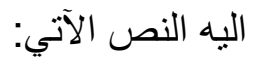

"كما ان طرف الجدار يعود إلى فلان ا وفلان r، فان فلان ا قد اخبر (فلان r) بإعادة بنـاءه بالكامل وان فلان ب قد قام بإعادة بناءه"(ro). النص اعلاه يشير إلى اجر اء عملية تجديد للجدار فاصل بين بيت عن طريق اعاده بنـاءه بالكامل وهذا الاجر اء هو نوع من الصيانة الجزئية لأحدى اجزاء المظهر العماري. ومن الامور الاخرى التي تضمنتها النصوص المسمارية العلاقات الاجتماعية بين افر اد المجتمع؛ إذ اشتارت إلى انه بعد انتقال الثخص إلى بيته الجديد سو اء بعد تجديده ام بناء لاول مره مبادرة الافر اد بتهنتته وارسال الهدايا إليه تعبير اً تقدير هم واحتر امهم. كما هو واضح في النص الآتي: "لقد أرسلت للك هدية لمنزل جديد"("r). ولم تتوقف اعمال الصبانة والترميم على افراد المجتمع المدني و انمـا كـان للسلطة الحاكمـة دوراً في تللك الاعمال ايضاً، وما يثبت اهتمامها بهذا الامر ما نصت عليه النصوص القانونية من مو اد نتعلق بالجانب العماري من وضعها الثروطو الآليات التي عن طريقها حفظت حقوق الافر اد اثناء تعـاملهم من هذه الناحية 
على مختلف انشطتها وصيغها؛ إذ تضمنت شريعة حمور ابي مجموعة من النصوص القانونية التي راعت مهنة المعماريين، وكذلك وضعت آلية القصاص على اصحاب هذه الحرف إذا ما قصروا في أداء عملهم على الى نئ

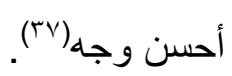

وقد اثـارت النصـوص الملكيـة العائدة إلى ملـوك العراق القديم إلى قيـامهم بأعمـال تجديد البيوت

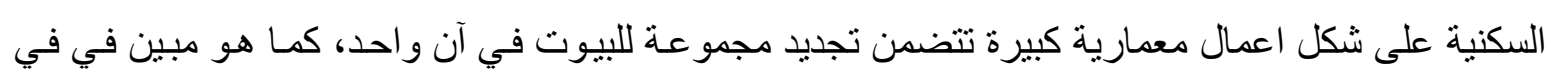

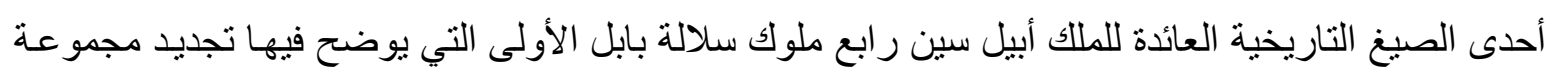
من بيوت السكن الو اقعة على ضفاف نهر دجلة(^ّ) كما هو واضح في في النص التالي:

\section{"السنة التي (أبيل سين) جدد مساكن وحقول على ضفاف نهر دجلة"(؟؟).}

يضاف إلى ذلك الاعمال التي قام بها الملك سرجون الأشتوري الذي يخبرنـا في احدى نصوص عن قيامة بترميم مجمو عة من المستوطنات السكنية المدمرة، كما في النص التالي:

"أنـا سـرجون الملك الباحث المستقصس.. احمل كلمـات الرحمـة واجدد المستوطنات التي اصـابها

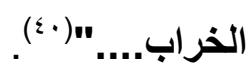
وبطبيعة الحال ان مجموع هذه المستوطنات التي تتكون من بيوتات المو اطنين تكون المدن التي تضم

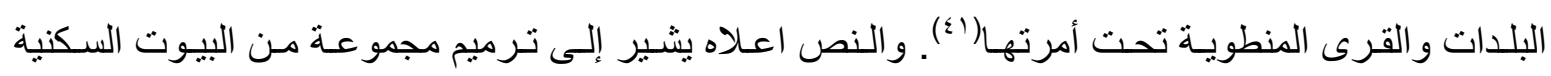
الخاصة بالأفر اد بعد ان لحقت بها الاضر ار جر اء الحروب. و هذا الامر نجده نادراً في اخبار الملوك في العراق القديم من تجديد بيوت السكن فهم لم يهتموا في

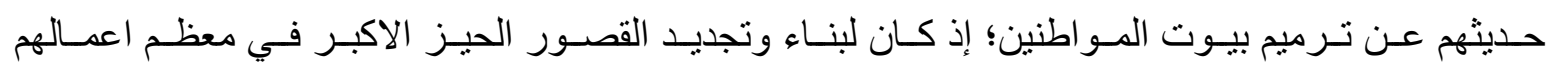
المعمارية(r؟). و هذا الأمر سوف نلمسه بصورة أكبر في المو اضيع الخاصـة بترميم المدن وملحقاتها. كما ان

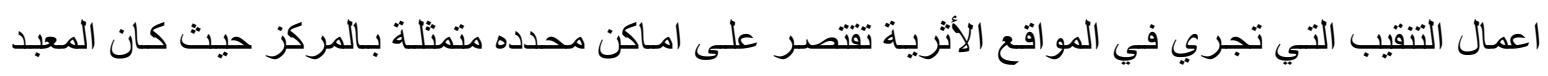

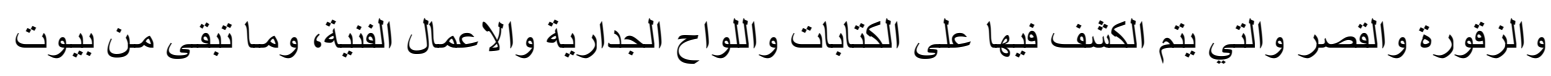

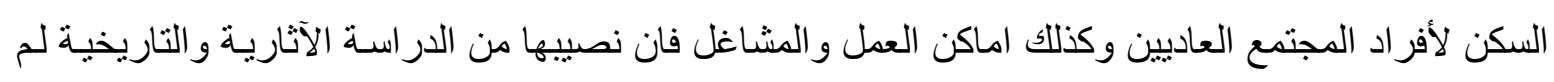

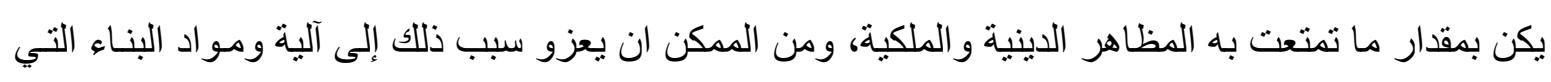

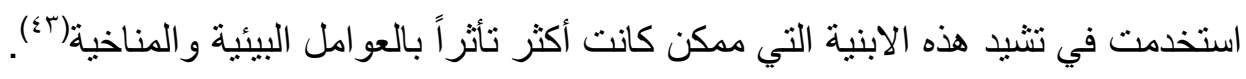

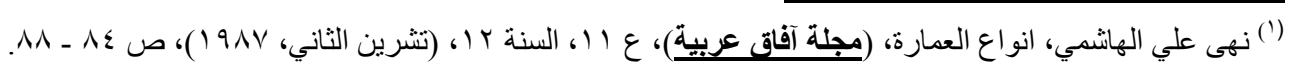
(r)

(ז) لقد شهدت الجانب الزراعي في حضارة العراق القديم تطوراً ملحوظاً منذ بداية اكتشاف الزراعة وصو لاً إلى العصور التاريخية؛ إذ عمل

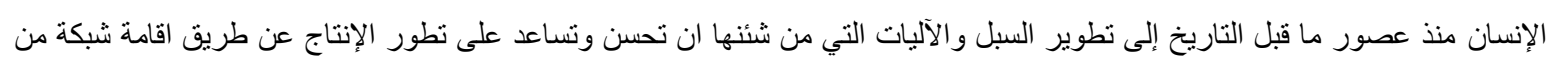

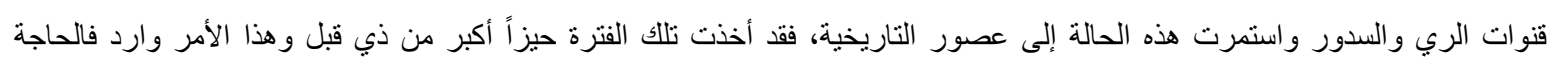

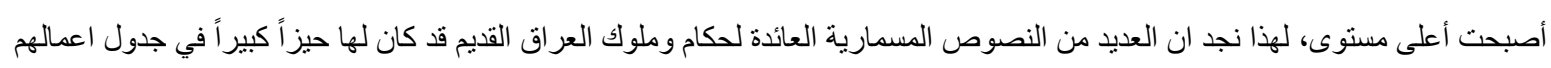

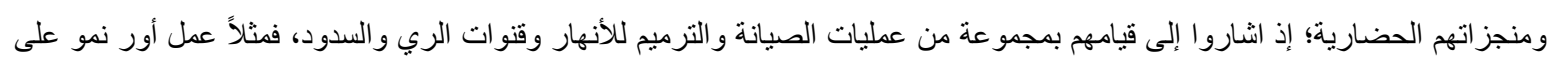


إعادة بناء نظام الري كاملاً في القسم الجنوبي بعد فترة من الاهمال والتدهور، كذلك نجد حمورابي يشير في كتاباته إلى اصلاح الانهار

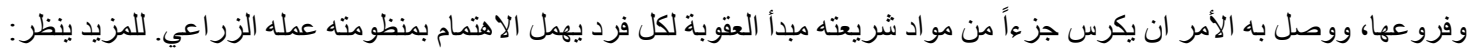
Renger, J., Rivers watercourses and ditches, irrigation, Within a book, Irrigation and Cultivation in Mesopotamia Bulletin on Sumerian Agriculture, Vol. V, Part. II, (Cambridge, 1990), p. 36.

() فاضل عبد الواحد علي، المعبد والزقورة: اثنان من ابرز السمات المعمارية في المدينة العراقية القديم، دراسات في الآثار والتاريخ،

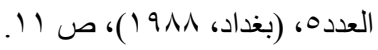

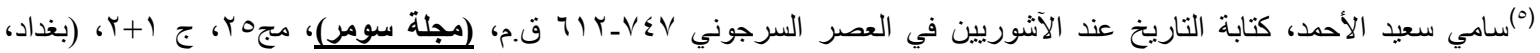
.0. ص) (1979

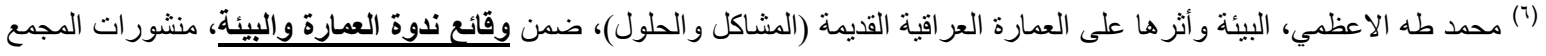

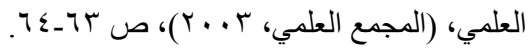

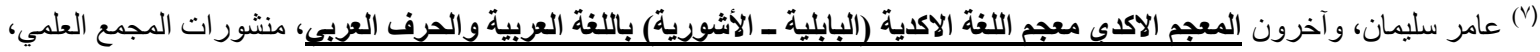

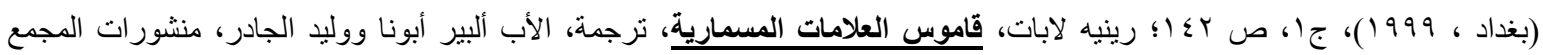

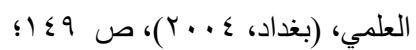

Gelb, Ignace J., and Others, The Assyrian Dictionary of the Oriental Institute of the University of Chicago , Vol. 2, (Chicago - Illibois, 1965), p. 282, CAD,

$$
\text { (^) }
$$

${ }^{(9)}$ CAD, B, Vol. 2, p. 282.

(·) كهلان خلف متعب القيسي، البيت العراقى فى العصر البابلى القديم في ضوء تنقيبات سبار، (جامعة بغداد ـ كلية الآداب، 9 (199)، رسالة ماجستير غير منشورة، ص 0.

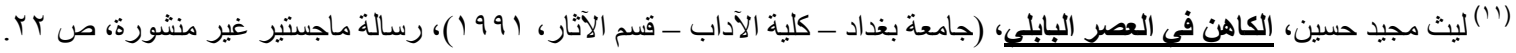
(r)

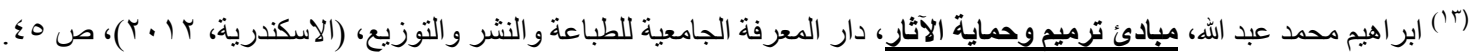

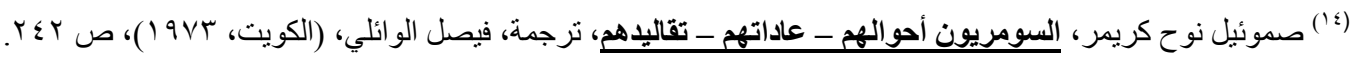

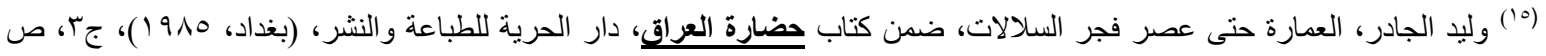

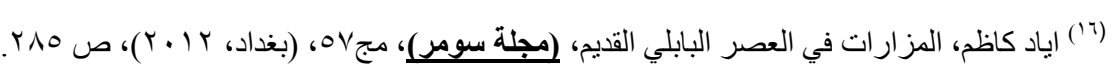

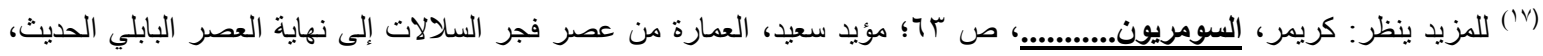

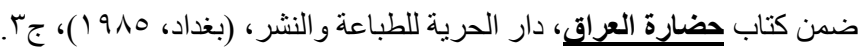

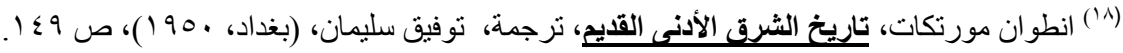

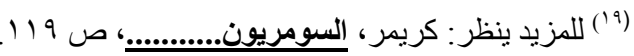
(·r) غولايف، المدن الأولى (ما بين النهرين مهر الحضارة البشرية)، ترجمة، طارق معصر انىى، دار التقدم موسكو، (الاتحاد السوفيتي،

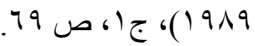

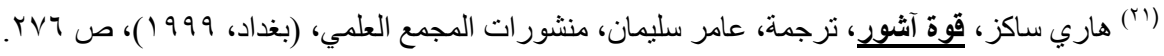
: (r)

Luckenbill, Daniel David, The Annals OF Sennacherib, Vol. II, (Chicago, 1924), pp. 151-153, OIP.

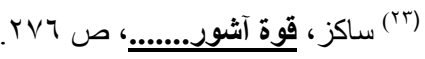

(24) Gelb, Ignace J., and Others, The Assyrian Dictionary of the Oriental Institute of the University of Chicago , Vol. 4, (Chicago - Illibois, 1958), p. 374, CAD,

${ }^{(26)} \underline{\text { CAD }}$, E, Vol. 4, p. 192.

${ }^{(27)}$ Ibid, p. 240 :b 


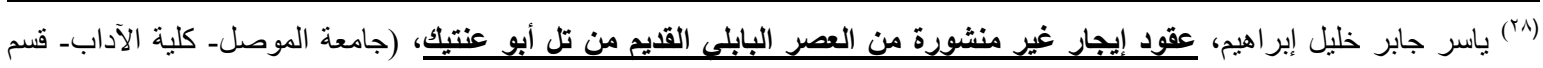

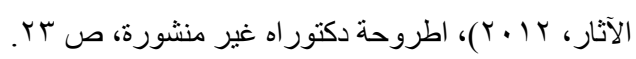

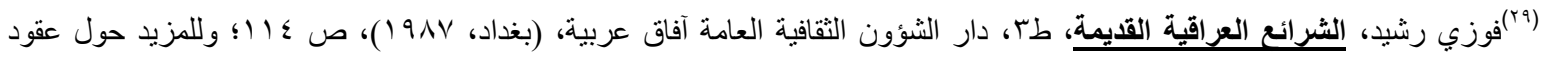
الايجار في العراق القديم ينظر :

Johns, C. H. W., M.A, Babylonian And Assyrian Laws, Contracts and Letters, (New York, 1904); Driver, G.R., and Miles, J.C., The Babylonian Laws, Vol. II, (Oxford, 1955).

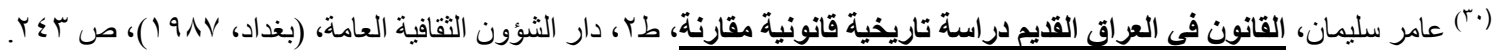

(31) Civil, Miguel, and Others, The Assyrian Dictionary of the Oriental Institute of the University of Chicago, M/1, Vol. 10, (Chicago - Illibois, 1977), p. 203, CAD.

${ }^{(32)}$ Ibid, p. 204.

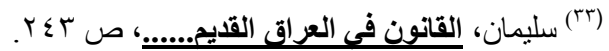

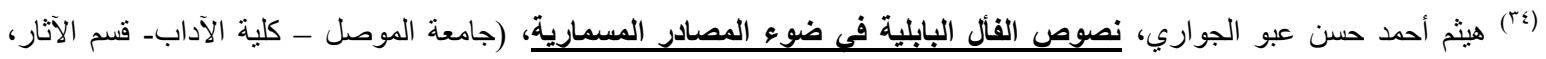

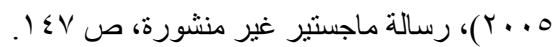

(35) Figulla, H.H., and Martin,, Letters and Documents of the old Babylonian Period, Vol, 5, (London,

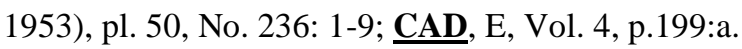

(36) CAD, E, Vol. 4, p. 374.

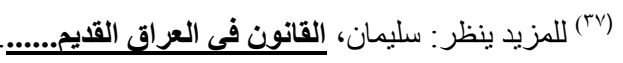

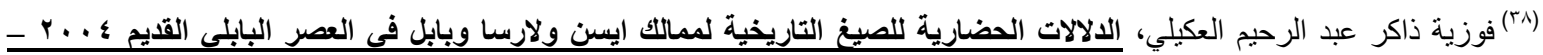

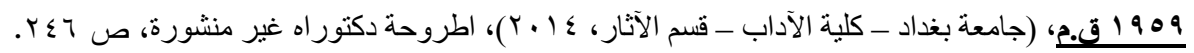

(39) Sigrist, Maecel, Mesopotamia Years Name New - Sumerian and Old Babylonian Date Formulae, (Berlin, 2001), p. 66, 12.b, MYN.

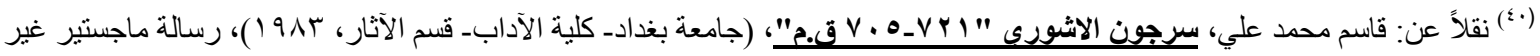

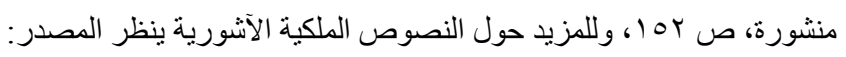

Luckenbill, Daniel David, Ancient Records Of Assyria and Babylonia, Vol. II, (Chicago - Illibois, 1927), ARAB.

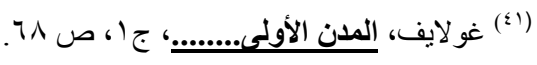

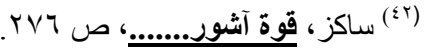

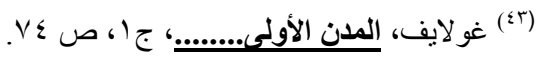

